\title{
Martha C. Nussbaum, La monarquia del miedo: una mirada filosófica a la crisis política actual
}

(2019) Paidós

Barcelona, 304 pp.

\author{
Emanuela Cardoso Onofre de Alencar* \\ Universidad de Barcelona \\ ORCID ID 0000-0001-8854-6291 \\ emanuela_alencar@hotmail.com
}

\section{Cita recomendada:}

Cardoso Onofre de Alencar, E. (2020). Martha C. Nussbaum, La monarquia del miedo: una mirada filosófica a la crisis política actual. Eunomía, Revista en Cultura de la Legalidad, 18, pp. 449-451.

doi: https://doi.org/10.20318/eunomia.2020.5294

En su último libro traducido al español, La monarquía del miedo, la filósofa estadounidense Martha $\mathrm{C}$. Nussbaum sigue desarrollando un tema en el que lleva trabajando un largo período: las emociones humanas. En esta obra, el miedo ocupa un lugar central en su reflexión.

El libro está subtitulado Una mirada filosófica a la crisis política actual. Eso podría inducirnos a pensar que la autora dedica su análisis a las tensiones políticas de carácter marcadamente emocional que polarizan la vida pública-política actual de su país. Sin embargo, aunque Nussbaum presenta argumentos que nos ayudan a comprender y analizar el estado emocional de nuestras sociedades democráticas actuales -no solo de la estadounidense-, su mirada es más amplia y se dirige a los efectos de ciertas emociones en la convivencia social, algo que no es exclusivo de nuestro periodo.

Para eso, Nussbaum toma una decisión metodológica que, en mi opinión, es importante: aunque algunas veces ilustra su razonamiento con hechos políticos actuales, opta por usar ejemplos históricos, especialmente de la Grecia y la Roma

\footnotetext{
* Docente e integrante del Instituto Universitario de Estudios de la Mujer - IUEM-UAM. Doctoranda en la Facultad de Derecho de la Universidad de Barcelona.
} 
antigua. Como su objetivo es invitar a sus lectores a la reflexión, a la introspección y a la argumentación crítica, Nussbaum cree que «solemos pensar mejor y relacionarnos de forma más eficaz unos con otros cuando tomamos cierta distancia de lo cotidiano, que es donde es más probable que estén centrados nuestros temores y deseos más inmediatos» (p. 40)

La tesis central del libro es que el miedo amenaza el funcionamiento de la democracia. El miedo es una emoción primitiva y natural en las personas. Nussbaum la vincula a la vulnerabilidad humana ante los complejos cambios socioeconómicos y políticos que generan exclusión, pérdida de calidad de vida e incertidumbre ante el futuro, y ante un «otro» amenazante, como pueden ser los inmigrantes, las minorías étnicas y religiosas, las personas LGTB o las mujeres.

Según Nussbaum, con frecuencia el miedo provoca otras emociones, como la rabia, el asco y la envidia. Estas emociones pueden cumplir un papel positivo o negativo. Si están vinculadas a una información falsa o deficiente, a una retórica incendiaria o a presiones sociales, pueden ser muy nocivas para la convivencia social. En su opinión:

Las emociones pueden desestabilizar una comunidad y fragmentarla, o bien pueden ayudar a que cooperemos mejor y a que pongamos mayor ahínco en conseguir la justicia. Las emociones no vienen predeterminadas de forma innata, sino que se van moldeando de innumerables maneras mediante los contextos y las normas sociales (p. 36)

De ahí que durante todo el libro defienda la necesidad de examinar lo que motiva esas emociones y de cambiar los aspectos sociales que fomentan su peor versión. Si no aprendemos a gestionar el miedo -y las demás emociones que analiza-, esa emoción amenaza el funcionamiento de las democracias, pues bloquea la deliberación racional, dificulta sentir esperanza y pon muchas barreras a la cooperación constructiva para promover un futuro mejor.

El abordaje de Nussbaum, como en sus obras anteriores, es holístico e interdisciplinar. El capítulo 2, «El miedo, temprano y preponderante» es uno de los más interesantes del libro. En él desarrolla la idea que titula su investigación. ¿Qué es la monarquía del miedo?¿Cómo el miedo puede cumplir un papel monárquico en una sociedad democrática?

La monarquía del miedo, según Nussbaum, es la condición de infancia perpetua. El bebé, vulnerable y amedrentado, necesita la atención y el cuidado continuado de su cuidador. El miedo, que expresa la vulnerabilidad humana, equipara así una persona adulta a un bebé, en la medida en que le hace dependiente de un individuo poderoso que le tutela y le protege ante el miedo a una amenaza. Ese individuo poderoso es como un monarca absoluto que se fortalece ante el miedo de sus súbditos, que les hace dóciles. El miedo facilita una especie de servidumbre voluntaria, en que quienes sienten miedo quieren protección y cuidado, y buscan a un gobernante fuerte que cuide de ellos. De ahí que con frecuencia le interese al monarca inspirar o promover el miedo en las personas.

Pero en una democracia, afirma Nussbaum, las relaciones interpersonales deben ser diferentes. La interacción entre las personas en su vida pública-política debe basarse en la cooperación, en la reciprocidad y en la confianza mutua. Confiar en alguien no es lo mismo que depender de alguien. La confianza requiere estar dispuesto a exponerse a otros ciudadanos, formar con ellos proyectos comunes y permitir que parte del futuro de unos esté en manos de otros. El monarca absoluto no quiere ni necesita la confianza de sus súbditos. 
Nussbaum no ofrece soluciones en su libro para combatir el miedo. «Este no es un libro sobre políticas públicas ni sobre análisis económico, por fundamentales que ambas disciplinas sean para resolver nuestros problemas. Es más general e introspectivo.» Lo que ella aspira a ofrecer son comprensión y guías generales para la acción.

[S]u objetivo primordial es la comprensión de la realidad. Comprender siempre tiene una vertiente práctica, claro está, pues sin una mínima comprensión de las cosas nuestro actos están condenados a carecer de objetivos concretos y a ser improvisados sobre la marcha (p. 35)

La principal dirección que Nussbaum ofrece está en el capítulo 7 «Esperanza, amor, visión imaginativa». Se trata del cultivo de la esperanza en las relaciones interpersonales, una emoción que se considera contraria al miedo, aunque comparta con éste diversos aspectos. Pero, según Nussbaum, la esperanza no es solo una emoción, sino que implica también una disposición de actuar. La esperanza hace mirar al futuro, a las posibilidades de cambio. Su concepción de la esperanza está inspirada especialmente en las enseñanzas y el ejemplo de Martin Luther King, Jr. y de Nelson Mandela. Nussbaum defiende que debemos cultivar la esperanza, la fe en la posibilidad de justicia y el amor. No el amor romántico, sino un amor que se asemeja al respeto a las personas: una manera de ver al otro en su humanidad, es decir, que es capaz de hacer algún tipo de bien y de cambiar. Eso no supone que la otra persona te guste o te caiga bien, sino que debes tener una actitud de apertura y de buena voluntad hacia ella, y que debes estar dispuesto a trabajar y a cooperar con ella.

La Monarquía del miedo es una obra en que Martha C. Nussbaum despliega la erudición a que nos tiene acostumbrados, y un conocimiento interdisciplinar de las emociones que analiza. Está escrita de una manera que, sin perder la profundidad en sus analices, está accesible a todos los lectores, no solo a los académicos. Es un libro muy recomendable tanto para quienes se interesan en estudiar las emociones humanas, como para quienes quieren comprender mejor el papel de las emociones en la vida pública-política y en el funcionamiento democrático. 